\title{
NOÇÕES SOBRE ENFERMEIRA NA REVISTA BRASILEIRA DE ENFERMAGEM: REFLEXÃO SOBRE IDEAL, CIÊNCIAE ARTE
}

\author{
BELIEFS REGARDING THE NURSING PROFESSION IN REVISTA BRASILEIRA DE \\ ENFERMAGEM (BRAZILIAN JOURNAL OF NURSING): REFLECTIONS ON THE IDEAL, SCIENCE \\ AND ART
}
NOCIONES SOBRE LA ENFERMERA EN LA REVISTA BRASILEÑA DE ENFERMERÍA: REFLEXIONES SOBRE IDEAL, CIENCIA Y ARTE

\author{
Estelina Souto do Nascimento ${ }^{1}$ \\ Geralda Fortina dos Santos ${ }^{2}$ \\ Valda da Penha Caldeira ${ }^{3}$ \\ Virgínia Mascarenhas Nascimento Teixeira ${ }^{4}$
}

\begin{abstract}
RESUMO: Com origem na indagação relativa às noções sobre enfermeira vigente durante as primeiras décadas da profissão no Brasil e ao fato de algumas delas permanecerem no presente, o estudo tem por objetivo resgatar as principais noções sobre enfermeira expressas pela "Revista Brasileira de Enfermagem". Abrangendo o período de 1932, ano em que foi criada a revista, até 1954. Foram analisadas 33 matérias. A partir da simbologia da capa da revista - mitologia egípcia; ideal, ciência e arte inscritos em um triângulo -, chegou-se a cinco categorias de enfermeira: a abnegada, a heroína, a socialmente comprometida, a mercenária e a anjo mau. A seguir, foi proposta uma significação para as idéias que figuram no triângulo. PALAVRAS-CHAVE: história da Enfermagem, identidade da enfermeira, noções de enfermeira, educação em Enfermagem
\end{abstract}

ABSTRACT: The inquiry of this study is the beliefs related to the nursing professional in the first decades of this activity in Brazil. The investigation presupposes that some of these beliefs are still current. The objective is to point out the beliefs expressed by Revista Brasileira de Enfermagem (Brazilian Journal of Nursing) in 33 articles, during the period between 1932 (when the journal was created) and 1954. Five notions of the nursing professional were identified through the analyses of the symbology presented on the cover of the periodical - Egyptian mythology; ideal, science and art, inscribed in a triangle. The categories established for nurses were: self-forgetful, heroine, socially committed, mercenary and bad angel. Finally, the study proposes an interpretation to the ideas presented in the triangle.

KEYWORDS: history of nursing, ideal nurse, beliefs on nurses, education in nursing, ideal, science and art in nursing

RESUMEN: Con origen en la indagación relativa a las nociones sobre la enfermera vigentes durante las primeras décadas de la profesión en Brasil y al hecho de que algunas de esas nociones permanezcan hasta el presente, el estudio tiene como objetivo rescatar las principales nociones sobre la enfermera que han sido expresadas por la "Revista Brasileira de Enfermagem". Hemos analizado 33 materias que abarcan los períodos, desde 1932 -año en que fue creada la revista-, hasta 1954. A partir de la simbología de la portada - de la mitología egípcia; ideal, ciencia y arte inscritos en un triángulohemos llegado a cinco nociones de enfermera: abnegada, heroína, socialmente comprometida, mercenaria y ángel malo. Al concluir, se propone un significado para las ideas que figuran en el triángulo.

PALABRAS CLAVE: historia de la profesión de enfermera, enfermera ideal, nociones de enfermera, educación en enfermeria, ideal, ciencia y arte en enfermería

Recebido em 31/08/2002

Aprovado em 27/09/2002

\footnotetext{
1 Enfermeira. Professora da Escola de Enfermagem da PUC-MG, membro do Núcleo de Pesquisas e Estudos sobre Quotidiano em Saúde - NUPEQS-MG. Doutora em Educação pela Faculdade de Educação da USP.

2 Enfermeira. Professora da Escola de Enfermagem da UFMG, membro do Núcleo de Pesquisas e Estudos sobre Quotidiano em Saúde - NUPEQS-MG. Doutoranda em Educação pela Faculdade de Educação da UFMG.

${ }^{3}$ Enfermeira. Coordenadora pedagógica do PROFAE da Escola de Enfermagem da UFMG, membro do Núcleo de Pesquisas e Estudos sobre Quotidiano em Saúde - NUPEQS-MG. Mestre em enfermagem pela Escola de Enfermagem da UNIRIO.

${ }^{4}$ Enfermeira. Membro do Núcleo de Pesquisas e Estudos sobre Quotidiano em Saúde - NUPEQS-MG. Mestre em Enfermagem pela Escola de Enfermagem da UFMG.
} 


\section{INTRODUÇÃO}

Nas últimas décadas, é crescente o número de trabalhos na área da Enfermagem que têm como tema a história da profissão sob diferentes perspectivas de discussão e reflexão. O fato de essa produção, de maneira geral, ser oriunda do meio acadêmico, permite-nos afirmar que alguns programas de pós-graduação em Enfermagem buscam incentivar este tipo de conhecimento.

Se o passado influi no atual, é, sem dúvida, fundamental a contribuição de estudos de natureza histórica, uma vez que podem trazer para o presente elementos que nos ajudam a melhor compreender a realidade atual. Como afirma Nunes (1996, p.19), "a história nos ensina não em função dos erros e dos acertos que devemos aprender a evitar ou assumir na realidade, e sim porque aguça a atenção para os rumos diferentes que toma segundo as intervenções que nela se operam". Além disso, continua a autora, a história é importante para o educador, qualquer que seja sua área de atuação, porque contribui para que "ele se mova no mundo de hoje com uma larga consciência de sua significação como sujeito histórico e cidadão, e uma lúcida visão dos seus impedimentos e, sobretudo, de suas possibilidades de interferência na realidade".

Como enfermeiras, algumas de nossas preocupações têm-se voltado para a compreensão da profissão, e uma das inquietações diz respeito às noções sobre enfermeira que nortearam a constituição do profissional durante as primeiras décadas da Enfermagem moderna no Brasil. Muito do que ocorreu no universo da Enfermagem permanece desconhecido por nós, bem como por nossos pares, em geral; todavia, perpassa o presente. Percebemos, no cotidiano, noções diversas sobre o profissional de Enfermagem as quais diriamos superadas; no entanto, constituem resquícios do passado.

Em estudo que trata de História da Educação, Lopes e Galvão (2001, p. 17) dizem que

\begin{abstract}
A história nos permite ver que, em outros lugares, culturas e em outras épocas, ou aqui perto de nós, a educação, de modo geral, e a escola, em particular, têm mudado, mas parecem manter alguns elementos intocados que, surpreendentemente, são os mesmos, aqui, em 2001, lá, em 1915. A História, dessa forma, ajuda-nos a olhar nossa realidade com paciência: afinal, as coisas demoram muito a mudar...
\end{abstract}

Quais as noções relativas a enfermeira vigentes durante as primeiras décadas da profissão no Brasil? O que dessas noções permanece intocado? Onde perscrutar essas questões? Um caminho possivel é o material publicado no início da profissionalização da Enfermagem no país. Elegemos, para este estudo, a Revista Brasileira de Enfermagem - REBEn -: além de haver sido o primeiro periódico da área, foi criada em 1932 pela Associação Nacional de Enfermeiras Diplomadas Brasileiras - ANEDB , hoje, Associação Brasileira de Enfermagem - ABEn -, é uma importante publicação até a atualidade.

Destarte, propomos, neste estudo, resgatar as noções sobre enfermeira veiculadas pelos Anais de Enfermagem, denominação da REBEn até 1954, já que esta revista é reconhecidamente um instrumento cujo objetivo é "servir de depositária das concepções que vão plasmando, moldando e dando existência à enfermeira nacional. Graças a existência da Revista, muitas idéias são produzidas, reunidas e difundidas" (EDITORIAL, 1962, p. 401).

\section{METODOLOGIA}

Tendo por finalidade resgatar as principais noções sobre enfermeira expressas nos Anais de Enfermagem, o processo de pesquisa se deu em dois momentos distintos. O primeiro refere-se à localização e à seleção do material; o segundo, à sua análise propriamente dita. Localizamos as revistas na Associação Brasileira de Enfermagem, Seção Minas Gerais - ABEn-MG -, e na Biblioteca J. Baeta Vianna, localizada no campus da saúde da Universidade Federal de Minas Gerais.

O material foi selecionado com base nos periódicos publicados de 1932 a 1954, um período de 22 anos. É importante salientar que não tivemos acesso ao número 2 de 1933, ao número 16 de 1939-1940, aos números 1 e 2 de 1948 e ao número 3 de 1953. Ademais, a partir de 1948, a revista começa uma nova seriação, com o volume 1.

Empreendemos a leitura da revista buscando as matérias que fazem referência a noções sobre enfermeira. Foram selecionados 33 artigos relacionados ao tema. Uma leitura atentiva permitiu-nos identificar categorias para exprimir as referidas noções. Tal critério culminou com a constituição de cinco noções: enfermeira abnegada, enfermeira heroina, enfermeira anjo mau, enfermeira mercenária e enfermeira socialmente comprometida.

Como a própria capa da revista, no periodo estudado, despertou-nos a atenção, também sobre ela realizamos uma análise.

Em suma, nosso estudo iniciou-se pelos símbolos da capa da revista, centralizou-se no triângulo que figura na capa e, a seguir, redirecionou-se para as categorias empíricas, que, em nosso entendimento, traduzem as noções sobre enfermeira veiculadas pelos Anais de Enfermagem.

\section{ARTE, CIÊNCIA E IDEAL}

No periodo recortado para este estudo, a revista teve duas denominações: Annaes de Enfermagem e Anais de Enfermagem. A capa, por sua vez, sofreu três modificações; a última ocorreu em 1955, ocasião em que "passou a variar de cor conforme o número da publicação; os símbolos egípcios foram abandonados e em seu lugar surgiu a figura estilizada da "dama da lâmpada", encimada pelo título da revista, em letras minúsculas, em itálico" (CARVALHO, 1976, p. 345). Os primeiros números trazem, em toda a extensão da capa, duas colunas com simbolos egipcios; entre elas, há um pedestal, sustentando um triângulo eqüilátero; no primeiro plano, embaixo, em frente às colunas, ladeando o pedestal, encontram-se duas esfinges. O triângulo traz inscrita, na base, a palavra Ideal e, nas laterais, Sciencia e Arte (Figura 1). A partir de 1946, a revista passa a se denominar Anais de Enfermagem, e sua capa é reestruturada. O mesmo símbolo, em tamanho reduzido, é colocado à esquerda nas capas das revistas de 1946 e 1947 e é centralizado até 1954. 
Figura1 - Capa dos Anais de Enfermagem

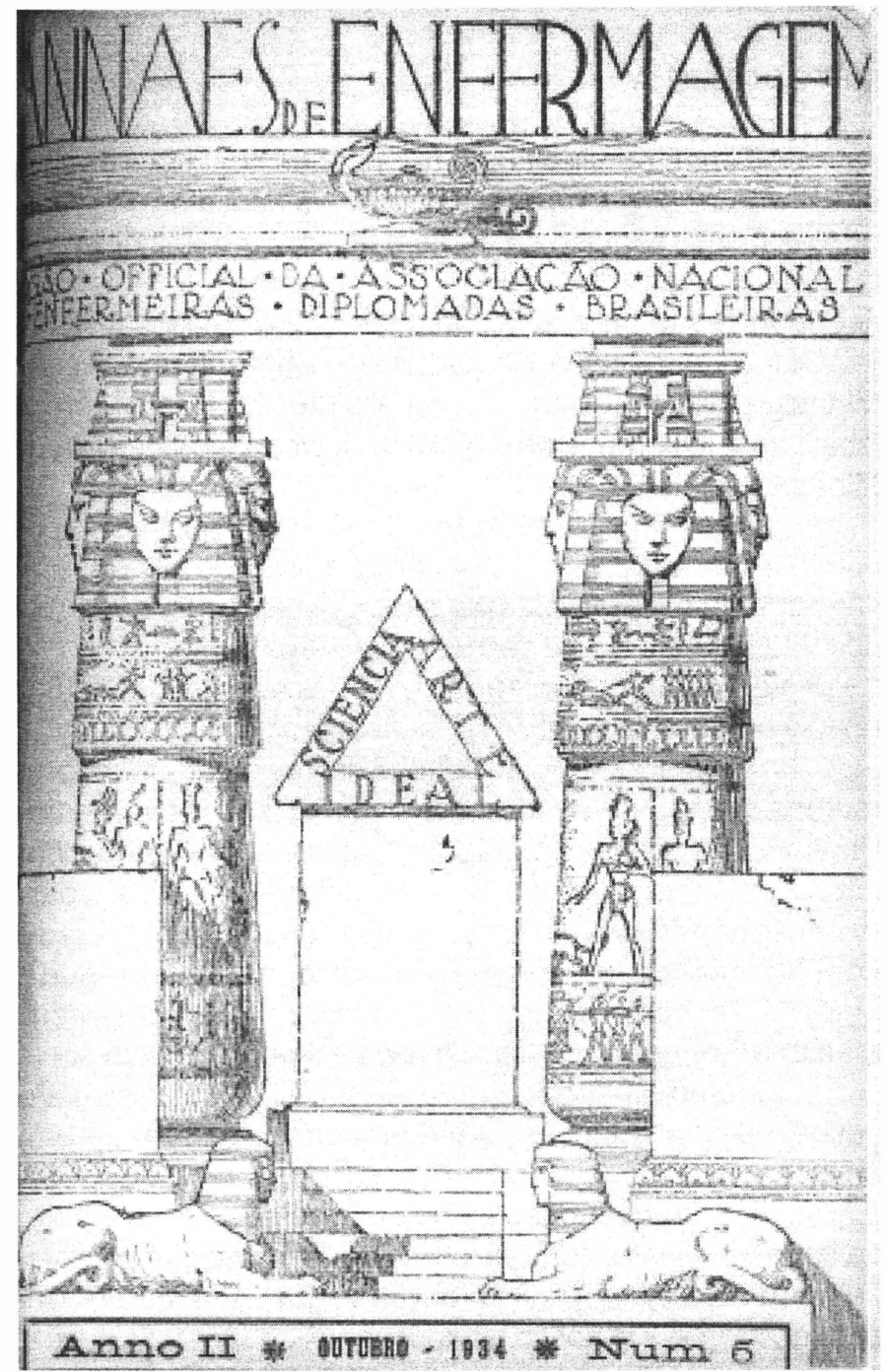

O que levou as idealizadoras da revista a esse tema para a capa? Segundo Carvalho (1976, p.332), em reunião informal da ANEDB, Rachel Haddock Lobo, então presidente dessa Associação, apresentou às associadas o "croqui" e as principais caracteristicas que a revista teria: "título seria Anais de Enfermagem, e a capa, idealizada e desenhada por um seu sobrinho, estudante da Escola de Belas Artes, teria o simbolismo dos monumentos egipcios como tema; seria de cor verde, tendo, centralizado, o triângulo projetado por Isabel Stewart, enfermeira norte-americana, com o lema, Ciência, Arte, Ideal".

Lopes (1934, p.3), em editorial do número quatro dessa publicação, afirma que "Anais de Enfermagem não poderia fugir à sedução que aquele povo [os egipcios] misteriosamente exerce sobre os que cultivam a história da civilização". Assim, a mesma autora diz que compreende a escolha da arte egipcia como "tema da capa". Talvez buscando compreender essa escolha, Lopes apresenta, nesse editorial, descrições de alguns deuses egípcios apresentados.

Também seduzidas e inspiradas pela mitologia egípcia, passamos a visualizar possiveis relações entre a idealização da enfermeira e a daqueles deuses. Assim, o Ideal seria representado por Nuit - Nut -, deusa do céu, que, de acordo com Étienne (1998), engole o sol e traz a noite, mas traz também as estrelas para iluminá-la, bem como ajuda os mortos a se unirem aos corpos celestes. Cuida do sol e das estrelas integrando-os em seu corpo. Além disso, conforme Lamas (1991, p.226), "esta deusa é muitas vezes representada como uma mulher de corpo esticado, erguida sobre a ponta dos dedos das mãos e dos pés, fixados na terra; o seu corpo estrelado, mantido no ar por Chu, forma a abóbada celeste". Paixão (1979, p.20) afirma que, no trabalho da enfermeira, o elemento principal é o ideal, que ela denomina espírito de serviço. Segundo Paixão, este

Foi o primeiro em ordem cronológica e é o primeiro na importância. Quando ainda não havia ciência, era o espirito de serviço que realizava, já embrionariamente, aquilo que ainda hoje constitui alguns dos objetivos da enfermagem: dar conforto físico e moral ao doente, afastar dele os perigos, ajudá-lo a alcançar a cura. A arte foi-se formando em seguida, de mistura com supertições e conhecimentos empiricos. Só mais tarde veio a verdadeira ciência.

Rá - Rê, o deus do sol, dádiva concedida a todos os homens, ilumina o país com sua beleza; senhor do céu (ÉTIENNE, 1998). Entendemos que Rá também representaria o Ideal. Este deus, como toda noção que incorpora o sentido de ideal, faz-nos lembrar algumas das chamadas precursoras da Enfermagem, como Santa Catarina de Siena, que, segundo Paixão (1979, p. 43), "é um nome que deve ser guardado pelas enfermeiras como uma das mais perfeitas realizadoras do seu ideal". Ela não se contentava em servir doentes no hospital; procurava por eles pelas ruas e os internava. Outra precursora é Florence Nightingale, considerada como mito e idealizadora da Enfermagem moderna. Movida também por um grande ideal, pode ser considerada como uma deusa dos feridos na guerra da Criméia: em sua solicitude, chegava ao "ponto de percorrer as enfermarias, à noite, com sua lâmpada, que era um raio de esperança para os feridos" (PAIXÃO, 1979, p.70). De acordo com Lamas (1991, p.218), Rá, ao envelhecer, refugiouse no ponto mais alto da abóbada celeste, levado pela deusa Nuit. Ali, vivia tranqüilamente, "sem alterar nunca o seu horário: durante as doze horas do dia percorre o seu império de Oriente para Ocidente, procurando sempre evitar o seu inimigo mortal, Apofis". Acrescenta que "durante a noite corre os maiores perigos, de caverna em caverna, mas sai sempre vencedor e reaparece, com o seu brilho ofuscante, para iluminar o mundo durante o novo dia".

Outro deus é Hathor, "divindade egípcia, cujo nome significa 'deusa da fecundidade': - a força semeadora, germinadora e construtura do mundo sob os seus mais belos aspectos de realização, abundancia e felicidade" (LOPES, 1934, p.3); representaria a Arte. Neste sentido, a arte está relacionada com a prática, a "enfermeira construtora", o que implica em ter habilidade, capacidade executiva e condições de avaliar o trabalho da enfermeira. Como afirma Vidal (1934, p.12), "é com o conhecimento da sua habilidade - capacidade executiva - que vamos avaliar a sua capacidade profissional, pois a arte representa a aplicação pratica dos conhecimentos científicos".

Por outro lado, a arte pode ser pensada não apenas na prática pela prática, ou na linearidade da aplicação prática da ciência da enfermagem; Ferreira (1986, p.176) nos informa 
que uma das acepções de arte é a "capacidade que tem o homem de pôr em prática uma idéia, valendo-se de sua capacidade de dominar a matéria"; em outra acepção, "a utilização de tal capacidade, com vista a um resultado, que pode ser obtido pormeios diferentes". Lalande (1992, p.79) refere-se à arte, entre outros sentidos, como o "conjunto de procedimentos servindo a produzir um certo resultado". A partir dessas noções de arte, podemos pensar a enfermeira utilizando a criatividade, a beleza, a música, a literatura, a sensibilidade, enfim, diferentes meios para conseguir atingir os resultados de seu trabalho que estão relacionados com o cuidar do outro com qualidade, eficiência e efetividade. Assim, a arte poderia, realmente, estar relacionada com o deus Hathor, que desempenha alguns papéis como os descritos por Lamas (1991, p.226): "Entre as suas atribuições contavam-se o amor, a alegria e a navegação. Protegia as mulheres, a cuja elegância presidia; proclamaram-na soberana da dança, da música, do canto, dos saltos e do enlaçamento das grinaldas".

E a Ciência, por sua vez, seria representada por Thot - Tot -, que, segundo Étienne (1998), é o sábio, o sabedor, o mágico, o inspirador da ciência. Corresponde a Hermes na mitologia grega e a Mercúrio na romana. Lamas (1991, p.216) afirma que ele é "adorado em todo Egipto como deus lunar, inventor da linguagem falada e escrita, das artes, das ciências, das invenções e da sabedoria [...]".

Considerada por Vidal (1934, p.12) como a segunda qualidade necessária à enfermeira, a ciência é o que diferencia esta dos atendentes de enfermagem, que dominam somente a prática. Assim, segundo a autora, "[...] a ciencia que nos distingue das atendentes. É ela que eleva o padrão da nossa profissão. De que nos valeria a pratica, sem o estudo cientifico?". Acrescenta que "a enfermeira essencialmente pratica não é perfeita, assim como a cientifica não é completa. É necessário, portanto, que a pratica esteja aliada à teoria para que possamos ter o tipo da enfermeira ideal".

Na cena da Enfermagem, conjugam-se, então, Hathor, a deusa das mulheres, deusa mãe, deusa do amor; Nuit - Nut, a deusa da noite, deusa do céu; Rá - Rê, deus sol; Thot - Tot, deus do conhecimento, deus da sabedoria.

Neste contexto, em que se conjugam divindades, ideal, arte e ciência, cabe retornar no tempo para fazer aflorar as noções sobre enfermeira. Lobo (1932b, p.5), ao traçar o surgimento e o desenvolvimento da Enfermagem, apontanos algumas pistas importantes. Segundo ela, é na Índia que desabrocharam as primeiras manifestações da Enfermagem. Desse povo, recebemos exemplos do "auxilio mútuo - alma da enfermagem". Sempre entregues ao sexo feminino, os ritos de cura, conforme a autora, passavam de avós a mães e filhas. Posteriormente, diz ela, "a enfermagem se elevou aos templos, onde era praticada sob forma mythologica, desde que aos deuses era dada a faculdade de fazer adoecer segundo a gravidade do pecado, pois a doença era a punição dos deuses para os pobres mortaes".

Tais crendices desapareceram e, segundo a autora, deram lugar às teorias científicas, que tiveram início com Hipócrates. Completa afirmando que é com os romanos, influenciados pelo cristianismo, que há "a expansão da enfermagem representando o mais perfeito espírito de humanitarismo", trazendo, assim, à tona "a mais viva manifestação de altruísmo feminino" (p.5). Posteriormente, continua ela, a partir das cruzadas, foram formadas ordens militares destinadas à prática da enfermagem. Estas atraíram para a enfermagem a aristocracia e tornaram a enfermeira uma fidalga. Conclui que "O Christianismo, o Militarismo e a Aristocracia não lograram, porém crear o typo ideal da enfermeira por faltar-Ihes o essencial - uma educação apropriada" (LOBO, 1932b, p.5). Em conseqüência disso, a enfermagem caiu em decadência e surgiu um tipo longe do esperado: a enfermeira curandeira, inculta e inconsciente. Fraenkel (1932), em outro artigo, traça trajetória semelhante. A partir da descrição apresentada, Lobo (1932b, p.6) estabelece uma dupla tipologia: "[...] a enfermeira religiosa em geral nobre e sem preparo scientífico, mas guiada por grande idealismo religioso, considerando a enfermagem como um holocaustro, e a mercenária, ignorante, sem o mesmo espirito humanitário, visando a parte material da profissão". Nesse cenário, "surge, então, Florence Nightingale, que reunia em uma única pessoa, ideal humanitário, cultura intellectual básica e posição social destacada". Poderiamos asseverar que, com ela, fez-se de novo a luz na Enfermagem. Quem, senão a dama da lâmpada, para encarnar, a um só tempo, todos esses deuses e deusas? Como tão bem define Capriglione (1932, p.27), ao dirigir-se, em discurso, à primeira turma de formandas do Brasil: "Conheceis de sobra como era appellidada Nightingale, a dama da lâmpada. Só era conhecida pela sua sombra e a simples visão desta, dava allivio aos feridos de guerra". Se aos deuses era dada a faculdade de fazer adoecer segundo a gravidade do pecado, também Ihes era dada a possibilidade de aliviar o sofrimento, mediante a simples aparição. "Que dizer do serviço anonymo executado em um recanto de enfermaria?! Doentes que vão e doentes que vêm. Não há nada de mais significativo. É o trabalho sem recompensa no momento, porém é a consciência de benefícios espalhados. Renan, em lapidar phrases nos diz: 'a certeza da recompensa mataria o merito'" (CAPRIGLIONE, 1932, p.27).

Diz, ainda, o autor: "sois heroinas, porque cultivaes um ideal” (p.27). Além desta missão preponderante, o autor afirma que o enfermeiro tem por nobre papel "colaborar na divina sciencia e arte". Diante disso, podemos concluir que o ideal é para "mulheres superiores", que colaboram com a ciência e com a arte.

O autor, ao falar das faculdades desenvolvidas pelas alunas formandas, aponta uma série de qualidades que interligam os lados do triângulo, mas enfatizam o ideal. São elas a "bondade intelligente, espontanea, generosa e sem excessos, a sympathia, a delicadeza de sentimentos, a cordialidade, a tolerancia, a vontade firme, o desprendimento, o poder convincente e a meiguice" (p.28). Completa:

É a vontade que estimula o trabalho e este é o melhor educador daquella. É ella que dá ao caracter a consciência do valor pessoal. Se é verdade que são as mulheres as que mais têm esses dons que as fizeram conductoras de idéas, não é menos verdade, que sem instrucção sólida, não há poder de iniciativa, espírito de observação ou noção de responsabilidade. Só tem conhecimentos destes, quem sabe analysar e só analysa quem tem instrucção (CAPRIGLIONE, 1932, p.27).

A idéia de conexão entre os lados do triângulo é 
assim expressa pelo autor: "Não se exige da enfermeira exclusivamente caridade e devotamento, e sim, intelligencia e rapidez de acção" (p.27).

A enfermeira, segundo Pullen (1934), deve possuir qualidades intelectuais, morais, físicas, emocionais e profissionais, bem como capacidade social. Esta envolve não só relações interpessoais entre enfermeiras, mas também o outro (doente) e a comunidade. Em artigo que fala da organização das escolas de Enfermagem, a autora destaca que é preciso levar em conta as necessidades reais da comunidade e as possibilidades de satisfazê-la (PULLEN, 1936). Assegura ainda: "[...] o objetivo de qualquer Escola de Enfermeiras deverá ser o de educar scientificamente suas alumnas, preparando-as para enfrentar problemas de saúde da communidade a que vae servir, sejam esses problemas: hospitalar, escolar, emergência, saúde publica ou serviço privado" (p.3).

Capriglione (1932, p.26) ressalta a função do hospital modemo, dizendo que este tem por finalidade "a conservação e a restauração da saúde":

Não é sómente um depositório de doentes agudos ou chronicos. Deve collaborar com outras instituições de ordem medico-social, afim de proteger a saúde da população, cuidar da reeducação dos enfermos curáveis ou não, tornar agradável a vida dos doentes chonicos e mentaes, pelas occupações e distrações, reintegral-os na familia e na sociedade. [...] À enfermeira de Saúde Publica é azado verificar que de nada vale por vezes a consulta ou a estadia num hospital, "se não se modificar a hygiene do lar, o local de trabalho, a alimentação, as condições proprias de trabalho, o somno, a actividade mental e emocional. Quanta vez é a doença aggravada ou entretida por condições sociaes que o medico desconhece; desde o aspecto architectonico ao interior da moradia, o papel della é ser traço de união entre o medico e a familia e entre os membros da familia".

Ademais, no discurso do autor, é possivel estabelecer, aliada ao compromisso social, uma ação heróica da enfermeira. Diz ele:

Partindo do facto de quasi todos os males da infancia advirem da pobreza e da ignorancia, procuraes com quem de dever, amparal-a e amparar os paes. Penetraes nas fabricas, officinas, de modo a ter sempre individuos sadios. Ajudaes a reeducar os enfermos, medida altamente conomica (sic) para o paiz e ensinaes os preceitos de hygiene, quando a exiguidade de hospitaes assim o exigir. Quanto beneficio! Que são patriotismo o de zelar pela saúde dos defensores da Patria. Crêde que nada mais é transitorio do que o culto da força: nada porém, mais estavel e firme do que as acções heroicas. Mudam-se as religiões, as idéas, a acção; porém o heróe é sempre lembrado. O sacrifício ao Bem é a nórma do heróe. É o sacrificio da alma que acolhe com firmeza e continuamente as dôres alheias.

Nada mais admirável do que vosso lemna.

“Do sacrifício surge a gloria." (CAPRIGLIONE, 1932, p.27)

Do exposto, podemos deduzir que o heroísmo da enfermeira tem origem no sacrifício que ela faz ao exercer a profissão. Tal sacrifício é ligado à sua vocação e à sua abnegação, qualidades, segundo Porto-Alegre (1935), básicas da enfermeira. "Sem vocação e sem abnegação fazse da enfermagem um meio de vida, um officio e não o que ela deveser: um sacerdocio" (p.12). Completa:

A verdadeira vocação que as faz deixarem posição, fortuna, parentes e amigos para dedicarem-se aos que sofrem. Quanto á abnegação, uma abnegação de coração, uma abnegação por assim dizer consciente como a do soldado que vê e conhece o perigo mas o enfrenta para salvar a Patria, essa tambem se encontra nas enfermeiras fieis ao seu ideal de altruismo, á sua vocação. É essa abnegação que faz as enfermeiras corajosas destemidas dedicarem-se ás curas das molestias contagiosas, das quais todos fogem, até os proprios parentes dos doentes; que as faz deixarem o conforto dos seus lares para passarem as noites em vigilia nos hospitais. E essa abnegação não existe quando não há vocação (PORTO-ALEGRE, 1935, p.12).

Esse pensamento é corroborado porPullen (1936, p.7) quando diz que "as enfermeiras são comosoldados em muitos casos. Devem estar promptas para agir, no momento preciso, em todas as circumstancias, sejam ellas quaes forem".

Ao falar da enfermeira heroína, Lobo (1932a, p.3) assim se expressa: "Nós Brasileiros temos um exemplo bello e bem frisante da mulher dedicação, da mulher patriota, da mulher energia, da mulher bem mulher, da mulher Mãe, na figura doce e tranqüila de Anna Nery". Essetipo de enfermeira é denominado anjo tutelar. "Na guerra, afrontando perigos de morte é a enfermeira o anjo tutelar dos soldados tombados no campo de batalha". (ANAIS DE ENFERMAGEM, 1946, p.20)

Portanto, é lícito afirmar que a enfermeira moderna, além de ser representante direta dos deuses e deusas citados, é o retrato dos temas que compõem o triângulo apresentado na capa da REBEn nas publicações das primeiras décadas. Ela é, ao mesmo tempo, sciencia, arte e ideal, uma vez que, segundo Lopes (1932), a enfermeira é companheira, mãe desvelada, técnica eficiente pelo estudo e conhecimento da ciência, observadora perspicaz, educadora dos lares e aperfeiçoadora da raça ${ }^{5}$. Paixão (1947, p.28) auxilia-nos nessa compreensão quando fala do desenvolvimento da profissão. Dizela: "Sondamos a História, e vamos colecionando os fátos mais característicos dessa evolução. Comparamos os diversos fatores, e a estrutura de uma enfermeira ideal se nos revela, resumindo-se nas três palavras do triângulo de Isabel Stewart: Ciência, arte, ideal".

Diante do exposto e retomando a simbologia da capa da revista (com o triângulo centralizado em relação aos símbolos egípcios), podemos dizer que a enfermeira ideal é aquela que incorpora, ou melhor, encarna o ideal, a arte e a ciência que se manifestam e podem ser identificados na sua atuação profissional.

A figura 2 mostra bem o que é necessário à formação da enfermeira moderna.

${ }^{5}$ Essa idéia de eugenia parece não haver tido repercussão posterior, além de 1930. 
Figura 2 - Característicos de enfermagem moderna

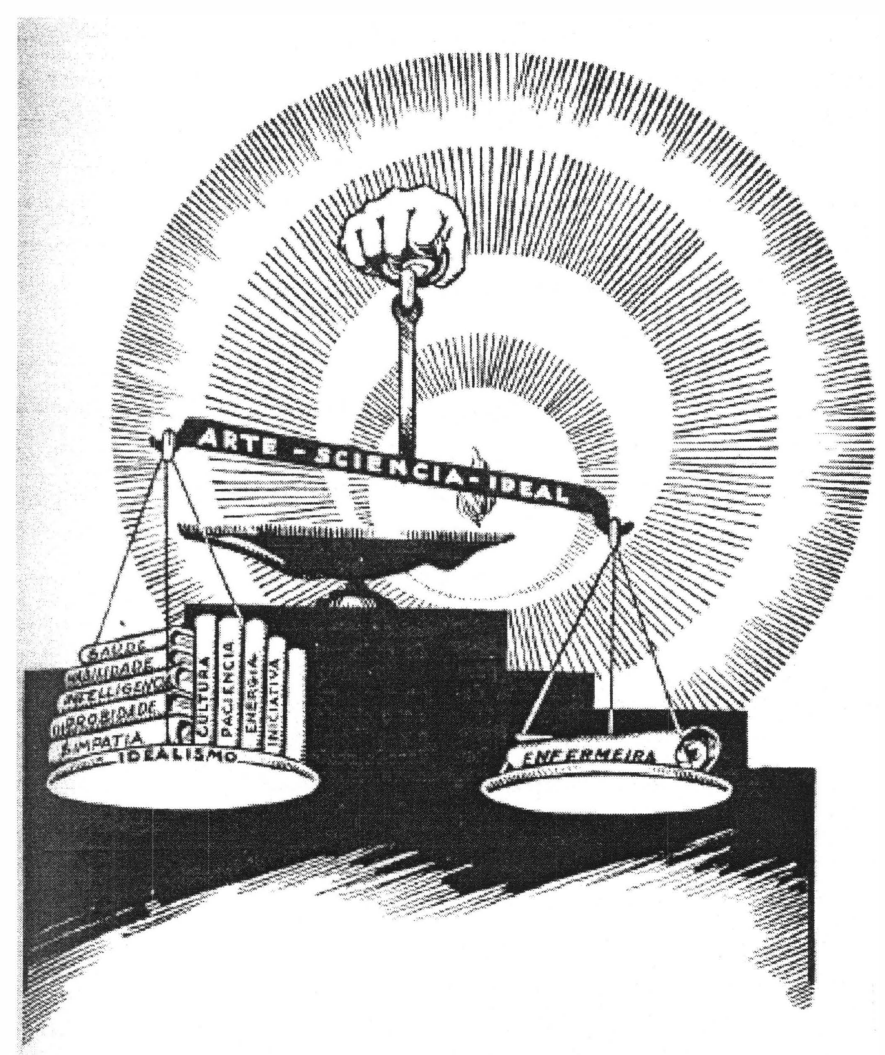

FONTE: ANNAES DE ENFERMAGEM (1934)

"A balança simboliza a justiça, o peso comparado dos atos e das obrigações" (CHEVALIER; GHEERBRANT, 1995, p.114). Para eles, "a balança é conhecida na qualidade de símbolo da justiça, da medida, da prudência, do equilíbrio, porque sua função corresponde precisamente à pesagem dos atos" (p.113). Nos pratos da balança, de um lado, o diploma, significando a enfermeira; do outro, as características necessárias para se fazer juz a essa certificação, as quais são fundamentadas na inscrição situada na barra da balança: arte, sciencia, ideal. Vale ressaltar que o prato que sustenta todas as características é o idealismo. Quando Chevalier e Gheerbrant (1995) falam de Deus, fazem uma ligação com essa temática dizendo que, "segundo o simbolismo anagenético de Paul Diel, as divindades simbolizam as qualidades idealizadas do homem" (p.114, grifo do autor). Podemos afirmar que, com essa relação - divindade e idealização -, completamos algumas voltas da espiral de nossa compreensão, que, embora avance, nãotem fim.

Além das duas noções apresentadas - a enfermeira religiosa e a enfermeira mercenária -, as quais escapam ao ideal de enfermeira preconizado pelo triângulo, identificamos uma terceira, a enfermeira anjo mau.

Mas, como se sabe, há anjos bons e anjos maus. Conheci algumas enfermeiras, - em minoria felizmente, - que se serviram de seu prestígio para fins repreensiveis, como, por exemplo, para explorar financeiramente seus clientes ou utilizá-los para a satisfação de um amor culpável.

$\mathrm{Na}$ verdade, seria um anjo mau a enfermeira que utilizasse seu prestigio para extorquir dinheiro de pobres indigentes, transformando assim sua bela profissão num odioso comércio.

Anjo mau, também, a enfermeira que sentisse prazer em despertar amor naqueles de quem cuidasse. Sem pensar no verdadeiro amor, divertir-se-ia com seus triunfos efêmeros, experimentando uma alegria diabólica em acender nos olhos de seus doentes a chama de um desejo perverso! (DESMARAIS, 1946, p.9).

$O$ autor denomina anjo mau, também, a enfermeira mercenária. Nós separamos os dois tipos: embora ambas utilizem-se da profissão, a primeira o faz para exercer a sedução; a segunda, para auferir lucro.

Quanto à noção de anjo mau, entendemos que, na atualidade, o fato de a enfermeira utilizar a sedução no desempenho do seu trabalho não a desqualifica. Em um ensaio sobre a imagem da enfermeira a partir da perspectiva formista, Rezende (1993, p.31) afirma que "sedução e feminilidade confundem-se ao longo da história humana, particularmente após o cristianismo, quando a mulher personificava o mal. Mas a sedução é mais vigorosa que a ordem que tenta destruí-la e, como a fênix, ressurge sempre das cinzas".

Em recente estudo realizado na França, Soliveres (2001, p.139) perguntou a sete enfermeiros - três homens e quatro mulheres - sobre a influência do sexo na relação de cuidado; obteve o seguinte resultado: "todos, exceto uma, reconheceram 'usar' de sedução em seu exercício". Assim, por ser uma característica feminina, acreditamos que a sedução é um componente de todas as noções que identificamos.

Podemos dizer, também, que o triângulo criado por Isabel Stewart ainda prevalece. A busca pelo ideal, pela arte e pela ciência nos remete às diretrizes constantes em um relatório elaborado para a UNESCO (DELORS, 2000), segundo o qual a educação deve fundamentar-se em quatro pilares. O primeiro deles, aprender a conhecer, tem como objetivo o domínio dos instrumentos do conhecimento. $O$ segundo, aprender a fazer, relaciona-se, além da competência técnica e profissional, à disposição para o trabalho em equipe, à capacidade de ousar e de tomar iniciativas. $O$ terceiro, aprender a viver juntos, remete à descoberta, ao reconhecimento do outro e à participação em projetos comuns. O quarto, aprender a ser, tem como objetivo preparar o ser humano para a autonomia intelectual e uma crítica da vida.

Sem analisar a evolução desses elementos e suas injunções diversas, pois não é esta a intenção de nosso estudo, propomos que seja atribuída nova significação ao triângulo de Stewart, conforme mostramos na figura 3, em que fazemos uma transposição para os quatro pilares propostos por Delors (2000). 
Figura 3 - Pilares da educação de enfermeiro

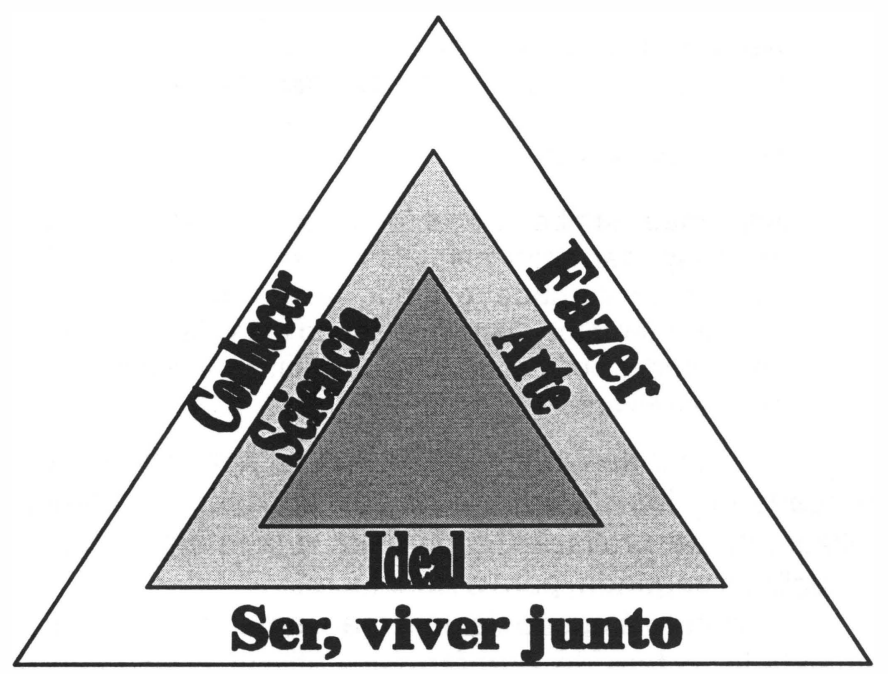

Entendemos que, ao primeiro dos pilares conhecer, corresponde o lado do triângulo denominado sciencia; ao segundo - fazer, corresponde a arte; aos dois últimos - ser e viver junto, corresponde o ideal. Dessa conjugação, podem-se ressaltar aspectos cognitivos, procedimentais e atitudinais na ação do enfermeiro, constituindo em uma triade indissociável na sua educação, a qual traz para o presente um novo olhar do passado. Longe de nós asseverar que o enfermeiro está estagnado nas décadas iniciais da profissão. Nosso intento é mostrar que, de alguma forma, o novo contém o velho. O retorno à citação de Lopes e Galvão (2001, p.17), apresentada na introdução deste trabalho, auxilia nessa compreensão final.

A história nos permite ver que, em outros lugares, culturas e em outras épocas, ou aqui perto de nós, a educação, de modo geral, e a escola, em particular, têm mudado, mas parecem manter alguns elementos intocados que, surpreendentemente, são os mesmos, aqui, em 2001, lá, em 1915. A História, dessa forma, ajuda-nos a olhar nossa realidade com paciência: afinal, as coisas demoram muito a mudar...

No âmbito deste trabalho, é impossivel aprofundar estas questões, portanto queremos deixar, com a recriação do triângulo de Isabel Stewart, certa dose de provocação, bem como pistas para outras pesquisas. Afinal, quem somos nós, enfermeiros, neste milênio que se inicia? Das noções vigentes no início da profissão no Brasil, o que permanece intocado ou adquiriu novo significado no imaginário dos enfermeiros e dos não-enfermeiros? Estas e muitas outras indagações estão a merecer investigação. A todos nós, o desafio!

\section{CONSIDERAÇÕES FINAIS}

Mediante a análise realizada, chegamos a cinco noções: enfermeira abnegada, enfermeira heroina, enfermeira socialmente comprometida, enfermeira anjo mau e enfermeira mercenária. Podemos dizer que as três primeiras eram enfatizadas não só pela revista como o tipo ideal da enfermeira, mas também defendidas por seus autores diversos: enfermeiros, estudantes de enfermagem, sacerdotes, médicos, entre outros.
Vale lembrar que a noção de enfermeira religiosa foi, de algum modo, incorporada à idéia de enfermeira abnegada: ambas contêm o idealismo religioso mediante a idéia, principalmente, de vocação e abnegação; a primeira, porém, não possui preparo científico. Percebemos, nesse tipo de enfermeira, que a religiosidade é um traço distintivo da profissão desde seus primórdios. Ademais, segundo Lobo (1932b) e Fraenkel (1932), o espírito humanitário do cristianismo aliou-se "ao mais perfeito altruismo feminino" (LOBO, 1932b, p.5).

Além disso, é possivel pensar que, a partir das cruzadas e com a formação das ordens militares destinadas à prática da enfermagem, esta passou a sofrer influência daquelas ordens, adotando uma hierarquia quase militar. Aliás, diriamos que esta perdurou até há pouco tempo e é possivel que dela haja resquícios ainda hoje. A enfermeira heroina pode haver surgido dai; comparada ao soldado, sua ação traz um paralelo com guerra, campo de batalha, dinamismo e força.

As noções que extraimos dos Anais de Enfermagem mostram-nos que a enfermeira deveria incorporar os atributos de ideal, arte e ciência. Acrescente-se que tanto a categoria da enfermeira heroina quanto da abnegada e da socialmente comprometida apresentam características que se imbricam, da mesma forma que a da mercenária e a do anjo mau têm elementos comuns. É importante ressaltar que o fato de havermos descrito e circunscrito estas cinco noções não quer dizer que elas se manifestem de forma pura, e que outras não possam existir.

\section{REFERÊNCIAS BIBLIOGRÁFICAS}

ANAIS DE ENFERMAGEM. Editorial. São Paulo, n.18, p.20, jan./mar. 1946.

ANNAES DE ENFERMAGEM. Editorial. Rio de Janeiro, ano 2, n.3, p.21, abr. 1934.

CAPRIGLIONE, L. Discurso. Annaes de Enfermagem, Rio de Janeiro, anno 1, n.1, p.26-28, maio 1932.

CARVAlho, A. C. de. Associação Brasileira de Enfermagem 1926-1976. Documentário. Rio de Janeiro: ABEn, 1976.

CHEVALIER, J.; GHEERBRANT, A. Dicionário de símbolos. 9.ed. Rio de Janeiro: José Olympio, 1995.

DELORS, J. Educação: um tesouro a descobrir. 4. ed. Brasilia: MEC/UNESCO, 2000.

DESMARAIS, M. M. Lições de psicologia aplicada à enfermagem. Anais de Enfermagem, São Paulo, n.18, p.913, jan./mar. 1946.

EDITORIAL. Anais de enfermagem, Rio de Janeiro, ano 15, n.5, p.401, out. 1962.

ÉTIENNE, M. Les dieux de l'Egypte: petit dictionnaire illustré. Paris: Musée du Louvre, 1998. 
FERREIRA, Aurélio Buarque de Holanda. Novo Dicionário Aurélio. Rio de Janeiro: Nova Fronteira, 1986.

FRAENKEL, E. A enfermagem no Brasil. Annaes de Enfermagem, Rio de Janeiro, anno 1, n.1, p.8-11, maio 1932.

LALANDE, A. Vocabulaire techinique et critique de la philosophie. 2.ed. Paris: PUF, 1992. v.1.

LAMAS, M. Mitologia geral: o mundo dos deuses e dos heróis. 3. ed. Lisboa: Estampa, 1991. v. 1.

LOBO, R. H. Um exemplo - Esboço biographico. Annaes de Enfermagem, Rio de Janeiro, anno 1, n.1, p.3, maio $1932 a$.

. Era nova. Annaes de Enfermagem, Rio de Janeiro, anno 1, n.1, p.5-6, maio 1932b.

LOPES, E. M. T.; GALVÃO, A. M. de O. História da educação. Rio de Janeiro: DP\&A, 2001.

LOPES, L. R. Símbolo. Annaes de Enfermagem, Rio de Janeiro, anno 2, n.4, p.3, jul. 1934.

NUNES, C. Os desafios da pesquisa histórica. Trabalho apresentado no 4. Encontro Nacional de História do Esporte, Lazer e Educação Física, Belo Horizonte, 1996.
PAIXÃO, W. História da enfermagem. 5.ed. Rio de Janeiro: Júlio C. Reis Livraria, 1979.

. Uma pioneira. Anais de Enfermagem, São Paulo, v.16, n.23, p.28, abr./jun. 1947.

PORTO-ALEGRE, I. de A. Vocação e abnegação. Annaes de Enfermagem, Rio de Janeiro, anno 3, n.6, p.12, jan. 1935.

PULLEN, B. L. Técnica da crítica construtiva. Annaes de Enfermagem, Rio de Janeiro, anno 2, n.5, p.14-16, out. 1934.

- Trabalho apresentado a III. ${ }^{\text {a }}$ Conferência PanAmericana da Cruz Vermelha. Annaes de Enfermagem, Rio de Janeiro, anno 4, n.8, p.2-9, nov. 1936.

REZENDE, A. L. M. A imagem da enfermagem na perspectiva formista. Enfermagem Revista, Belo Horizonte, v.1, n.1, p.25-36, abr. 1993.

SOLIVERES, A. P. Infirmières, le savoir de la nuit. 4.ed. Paris: PUF, 2001.

VIDAL, Z. C. O triângulo da enfermeira. Annaes de Enfermagem, Rio de Janeiro, anno 2, n.3, p.11-12, abr. 1934. 